\title{
Sports and energy drink consumption are linked to health-risk behaviours among young adults
}

\author{
Nicole Larson ${ }^{1, *}$, Melissa N Laska ${ }^{1}$, Mary Story ${ }^{2}$ and Dianne Neumark-Sztainer ${ }^{1}$ \\ 'Division of Epidemiology and Community Health, School of Public Health, University of Minnesota, Suite 300, 1300 \\ South Second Street, Minneapolis, MN 55454, USA: ${ }^{2}$ Global Health and Community and Family Medicine, Duke \\ University, Durham, NC, USA
}

Submitted 16 April 2014: Final revision received 1 December 2014: Accepted 16 December 2014: First published online 16 February 2015

\begin{abstract}
Objective: National data for the USA show increases in sports and energy drink consumption over the past decade with the largest increases among young adults aged 20-34 years. The present study aimed to identify sociodemographic factors and health-risk behaviours associated with sports and energy drink consumption among young adults.

Design: Cross-sectional analysis of survey data from the third wave of a cohort study (Project EAT-III: Eating and Activity in Teens and Young Adults). Regression models stratified on gender and adjusted for sociodemographic characteristics were used to examine associations of sports and energy drink consumption with eating behaviours, physical activity, media use, weight-control behaviours, sleep patterns and substance use.

Setting: Participants completed baseline surveys in 1998-1999 as students at public secondary schools in Minneapolis/St. Paul, Minnesota, USA and the EAT-III surveys online or by mail in 2008-2009.

Subjects: The sample consisted of 2287 participants ( $55 \%$ female, mean age $25 \cdot 3$ years).

Results: Results showed $31.0 \%$ of young adults consumed sports drinks and $18.8 \%$ consumed energy drinks at least weekly. Among men and women, sports drink consumption was associated with higher sugar-sweetened soda and fruit juice intake, video game use and use of muscle-enhancing substances like creatine $(P \leq 0.01)$. Energy drink consumption was associated with lower breakfast frequency and higher sugar-sweetened soda intake, video game use, use of unhealthy weight-control behaviours, trouble sleeping and substance use among men and women $(P<0.05)$.

Conclusions: Health professionals should consider the clustering of sports and energy drink consumption with other unhealthy behaviours in the design of programmes and services for young adults.
\end{abstract}

Keywords
Sports drinks
Energy drinks
Young adults
High consumption of sugar-sweetened beverages is at the forefront of public health concerns as previous research has shown that consumption is associated with numerous adverse health outcomes, including obesity, type 2 diabetes, increased risk for CVD and dental caries ${ }^{(1,2)}$. Despite evidence of a decrease in total sugar-sweetened beverage intake over the past decade, US national survey data documented an increase in consumption of sports and energy drinks ${ }^{(3)}$. The largest increase in sports and energy drink consumption has occurred among young adult (20-34 years) consumers of these sugar-sweetened beverages, with average daily energy consumption increasing from $498 \mathrm{~kJ}$ (119 kcal) in 1999-2000 to $958 \mathrm{~kJ}(229 \mathrm{kcal})$ in $2007-2008^{(3)}$.
Marketing for sports and energy drinks is often targeted to young adults, particularly males ${ }^{(4-6)}$. Sports drinks are marketed as a means for improving athletic performance and replacing electrolytes and fluids lost during intense physical activity $^{(5,7)}$. In contrast, energy drinks are marketed as a means for decreasing feelings of tiredness, boosting energy, enabling weight loss and enhancing mental alertness ${ }^{(8)}$. The high caffeine content and other stimulants in energy drinks that provide these purported benefits may also pose health risks to young adults, particularly when mixed with alcohol $^{(8-11)}$.

Most research designed to inform interventions for young adults has focused on the practice of consuming 
alcohol mixed with energy drinks and college students. While the risk-taking behaviours and potential severe consequences associated with consuming alcohol mixed with energy drinks warrant concern and energy drink consumption has been associated with higher alcohol use, prior studies suggest that the majority of energy drink consumption does not occur in combination with alcohol ${ }^{(10,12-14)}$. It may be that sports and energy drink consumption is part of broader behavioural patterns based on common psychological (e.g. enjoyment of sensation-seeking behaviour) or social (e.g. risk-oriented group membership) factors. There is thus a need for additional research to examine the co-occurrence of frequent sports and energy drink consumption with a wider spectrum of health behaviours that impact risk for obesity and chronic disease among young adults. Young adulthood has been identified as a high-risk period for the development of obesity, as well as unhealthy eating and physical activity patterns ${ }^{(15)}$.

The present study addresses the need for research to inform health programmes and services that meet the needs of young people during this high-risk life stage and will be among the first of US studies to distinguish between consumption of sports drinks and energy drinks in identifying sociodemographic subgroups of young adults in need of targeted interventions. Further, the study will identify patterns of health risk behaviours that cooccur with sports and energy drink consumption and may be important to understand in developing relevant intervention strategies to reduce consumption. As prior research has documented greater consumption of these beverages among males and it is likely that gender-specific factors influence consumption patterns, associations will be examined separately for males and females ${ }^{(16)}$.

\section{Methods}

\section{Study design and population}

Data for the current cross-sectional analysis were drawn from Project EAT-III (Eating and Activity in Teens and Young Adults), the third wave of an observational study designed to examine dietary intake, physical activity, weight-control behaviours, weight status and factors associated with these outcomes among diverse young adults. At baseline (1998-1999), a total of 4746 junior- and senior-high-school students at thirty-one public schools in the Minneapolis/St. Paul metropolitan area of Minnesota, USA, completed surveys and anthropometric measures $^{(17,18)}$. Ten years later, original participants were mailed letters inviting them to complete online or paper versions of the Project EAT-III survey and an FFQ. A total of 2287 young adults completed the Project EAT-III survey between November 2008 and October 2009, representing 66.4\% of participants who could be contacted ${ }^{(19)}$. All study protocols were approved by the University of Minnesota's Institutional Review Board Human Subjects Committee.

\section{Survey development and measures}

The original Project EAT survey that was used to assess determinants of dietary intake and weight status among adolescents was modified at follow-up to improve the relevance of items for young adults ${ }^{(18)}$. New items were also added to allow for investigating areas of growing interest such as consumption of sports and energy drinks. The revised survey was pilot tested to examine test-retest reliability over a period of 1-3 weeks and psychometric values are provided for each measure below when available. Additional details of the survey development process are described elsewhere ${ }^{(20)}$

\section{Sports and energy drink intake}

Usual past-year intake of sports and energy drinks was assessed on the EAT-III survey using two questions, which separately asked about the frequency of consuming each type of drink. Response categories included 'never or less than once per month', 'one to three per month', 'one per week', 'two to four per week', 'five to six per week', 'one per day' and 'two or more per day'. Popular brand-name examples were given for energy drinks (Red Bull ${ }^{\circledR}$, Full Throttle $^{\circledR}$ and Rockstar ${ }^{\circledR}$ ) and sports drinks (Gatorade ${ }^{\circledR}$ and Powerade ${ }^{\circledR}$ ). Based on the distribution of intake in the sample, analyses focused on weekly consumption of sports and energy drinks defined as consumption of at least one drink per week (test-retest agreement $=94 \%$ for sports drinks, $97 \%$ for energy drinks).

\section{Physical activity and media use}

Physical activity was assessed using questions adapted from the widely used Godin Leisure-Time Exercise Questionnaire $^{(21)}$. Three survey items individually assessed hours of strenuous, moderate and mild activity in a typical week, with several examples of each level of activity provided. Response options were 'none', 'less than 0.5 hours', '0.5-2 hours', ' $2 \cdot 5-4$ hours', '4.5-6 hours' and ' 6 or more hours'. Each response was assigned a midpoint value and responses were then summed to compute total weekly hours of physical activity (test-retest reliability $r=0 \cdot 80$ ). Responses for strenuous and moderate activity were also summed to examine total weekly hours of moderate-to-vigorous physical activity (test-retest reliability $r=0 \cdot 85$ ). Muscle-enhancing behaviours were assessed using two questions, which separately asked about changing one's eating or exercising more in order to increase muscle size or tone during the past year. Response categories for each item included 'never', 'rarely', 'sometimes' and 'often'; these responses were scored from 1 to 4 and summed such that higher values indicated more frequent use of muscle-enhancing behaviours (test-retest reliability $r=0 \cdot 77$ ). Participants indicated the average number of leisure-time hours they spent playing video games and watching television (TV), digital video discs (DVD) or videos separately for both weekdays and weekend days ${ }^{(22,23)}$. Response categories 
for each question were ' 0 hours', '0.5 hour', ' 1 hour', '2 hours', ' 3 hours', ' 4 hours' and ' 5 or more hours'; these responses were scored $0,0 \cdot 5,1,2,3,4$ and $6 \mathrm{~h} /$ week to create continuous variables representing total weekly hours of use (test-retest reliability $r=0.81$ for TV/DVD/ videos).

\section{Weight-control behaviours}

Dieting was assessed with the question "How often have you gone on a diet during the last year? By "diet" we mean changing the way you eat so you can lose weight.' Responses included 'never', 'one to four times', 'five to ten times', 'more than ten times' and 'I am always dieting'. Responses were dichotomized into non-dieters (responded never) and dieters (other responses; test-retest agreement = $97 \%)^{(24)}$. Unhealthy and extreme weight-control behaviours were assessed with the question: 'Have you done any of the following things in order to lose weight or keep from gaining weight during the past year?' (yes/no for each method). Responses categorized as unhealthy weightcontrol behaviours included: (i) fasted; (ii) ate very little food; (iii) used a food substitute (powder or a special drink); (iv) skipped meals; and (v) smoked more cigarettes. Extreme weight-control behaviours included: (i) took diet pills; (ii) made myself vomit; (iii) used laxatives; and (iv) used diuretics. For the separate measures of unhealthy and extreme behaviours, those reporting the use of one or more behaviours were respectively coded as using weightcontrol behaviours (test-retest agreement $=83 \%$ for unhealthy behaviours, $97 \%$ for extreme behaviours).

\section{Sleep patterns}

Sleep habits were assessed using measures drawn from a previously validated questionnaire ${ }^{(25)}$. Participants were asked when they usually go to bed and get out of bed separately for weekdays and weekend days. Average weekday and weekend day sleep durations were calculated from the times provided ${ }^{(26)}$. Overall average daily sleep duration was calculated as (weekday duration $\times 5 / 7$ ) + (weekend day duration $\times 2 / 7$ ). Adequate sleep was defined as a daily average of seven or more hours according to the Healthy People 2020 objectives. Having trouble going to sleep or staying asleep was assessed for the past year (test-retest agreement $=78 \%$ for 'somewhat' or 'very much' $v$. 'not at all').

\section{Substance use and risk taking \\ Participants reported cigarette smoking, binge drinking, marijuana use, steroid use and other muscle-building substance use (e.g. creatine, hydroxyl methylbutyrate) during the past year. Responses were dichotomized to examine at least weekly cigarette smoking (test-retest agreement $=95 \%$ ) and any past-year use of the other substances (test-retest agreement $=97 \%$ for marijuana, $100 \%$ for steroids, $100 \%$ for muscle-building substances). Binge drinking was assessed by asking participants how}

many times they had five or more drinks at a sitting over the past 2 weeks (test-retest agreement $=84 \%$ for any $v$. no episodes).

\section{Eating behaviours}

A semi-quantitative FFQ was administered at the same time as the Project EAT-III survey and used to assess usual past-year intakes of sugar-sweetened soda, caffeinated coffee and tea, $100 \%$ fruit juice and $\mathrm{milk}^{(27)}$. A daily serving was defined as the equivalent of one glass, bottle or can for sugar-sweetened soda; 8-16 fl oz (237-473 ml) for coffee and tea; one-half cup or a small glass for fruit juice; and one cup for milk. Previous studies have examined and reported on the reliability and validity of intake estimates $^{(28,29)}$. Responses to the FFQ were excluded if participants reported a biologically implausible level of total energy intake $(<2093 \mathrm{~kJ} / \mathrm{d}(500 \mathrm{kcal} / \mathrm{d})$ or $>20934 \mathrm{~kJ} / \mathrm{d}$ $(5000 \mathrm{kcal} / \mathrm{d}))$. To assess breakfast consumption, the Project EAT-III survey included the question: 'During the past week, how many days did you eat breakfast?' Five response options ranged from 'never' to 'every day' (test-retest reliability $r=0.82$ ).

\section{Sociodemographic characteristics}

Sociodemographic characteristics were self-reported and included gender, age, race/ethnicity, educational achievement, post-secondary student status, employment status, parental status and relationship status. Educational achievement was assessed with the question: 'What is the highest level of education that you have completed?' (test-retest agreement $=97 \%$ ). Post-secondary student status in the past year was reported according to whether young adults were enrolled full-time or part-time in a two-year college, four-year college or graduate degree programme (test-retest agreement $=95 \%$ ). Responses were dichotomized for analysis (student or not a student). Current employment status was assessed with the question: 'How many hours a week do you currently work for pay?' (testretest reliability $r=0.94$ ). Young adults who reported working $\geq 40 \mathrm{~h} /$ week were categorized as employed full-time. Six response options were provided for report of relationship status and were categorized according to whether young adults were single (single or casually dating, separated or divorced, widowed) or involved in a committed relationship (committed dating relationship or engaged, married, same-sex domestic partner) at the time of the survey (test-retest agreement $=98 \%$ ).

\section{Sensation-seeking behaviour}

Sensation-seeking behaviour was assessed with the question: 'Do you like to do things that are a little dangerous (for example, sky diving, bungee jumping, gambling)?' Responses were dichotomized to distinguish those who reported low enjoyment ('not at all' or 'a little') from those who reported high enjoyment ('quite a bit' or 'very much'; test-retest agreement $=94 \%$ ). 


\section{Weight status}

Weight status was assessed using self-reported height and weight, from which BMI $\left(\mathrm{kg} / \mathrm{m}^{2}\right)$ was calculated. Self-reports of height and weight (test-retest reliability $r=0.99$ for height and weight) were validated in a sub-sample of sixty-three male and sixty-two female participants in Project EAT-III for whom height and weight measurements were completed by trained research staff. Results showed very high correlations between self-reported BMI and measured BMI in males $(r=0.95)$ and females $(r=0.98)$. Weight status was defined according to current BMI guidelines for adults (not overweight: $\quad \mathrm{BMI}<25.0 \mathrm{~kg} / \mathrm{m}^{2} ; \quad$ overweight: $\mathrm{BMI}=25.0 \quad$ to $29.9 \mathrm{~kg} / \mathrm{m}^{2}$; obese: $\left.\mathrm{BMI} \geq 30 \cdot 0 \mathrm{~kg} / \mathrm{m}^{2}\right)^{(30)}$.

\section{Statistical analyses}

All analyses were conducted using the statistical software package SAS version 9.3 (2011) and stratified by gender. Descriptive statistics were first calculated to examine patterns of sports and energy drink consumption. The $\chi^{2}$ statistic was used to identify differences in weekly consumption according to sociodemographic characteristics, enjoyment of sensation-seeking behaviours and weight status. Linear and logistic regression models were used to estimate associations between weekly sports and energy drink consumption and health behaviours, while adjusting for those factors that have been identified as potential confounders in previous research ${ }^{(16,31,32)}$. One set of models included weekly sports drink consumption and each health behaviour of interest in a separate model. A second set of models likewise included weekly energy drink consumption to allow for separately examining associations with each health behaviour variable. To account for the potential influence of an underlying tendency to engage in risk-taking behaviours in terms of relationships with substance-use behaviours ${ }^{(33,34)}$, additional models were examined that adjusted for enjoyment of sensation-seeking behaviours.

Because attrition from the baseline sample (1998-1999) did not occur at random, the data were also weighted using the response propensity method for all analyses ${ }^{(35)}$. When compared with non-respondents in Project EAT-III, respondents were more likely to be female, white, younger and raised by parents of higher socio-economic status. Response propensities (i.e. the probability of responding to the Project EAT-III survey) were estimated by performing the logistic regression of response at EATIII $v$. a large number of predictor variables from the baseline Project EAT survey. Weights were additionally calibrated so that the weighted total sample sizes used in analyses accurately reflect the actual observed sample sizes for males and females. The weighting method resulted in estimates representative of the sociodemographic make-up of the original school-based sample, thereby allowing results to be more fully generalizable to the population of young people in the Minneapolis/St. Paul metropolitan area.
A $95 \%$ confidence level was used to interpret the statistical significance of probability tests, corresponding to $P<0 \cdot 05$. Whenever the dependent variable exhibited positive skewness, such testing was carried out under the square-root transformation after confirming the transformed variables better approximated normal distributions.

\section{Results}

\section{Beverage consumption frequency and associations with sociodemographic characteristics, sensation- seeking behaviour and weight status}

Sports drinks were consumed at least weekly by $31.0 \%$ of the young adult participants and energy drinks by $18.8 \%$ of participants. Only $12 \cdot 6 \%$ of young adults weekly consumed both sports and energy drinks. Weekly consumption of sports drinks was more common among males than females (44.6\% v. $19.9 \%, P<0.001$ ), and likewise weekly consumption of energy drinks was more often reported by males than females $(26.7 \% v .12 .2 \%, P<0.001)$. Approximately one quarter ( $24.1 \%$ of males, $23.5 \%$ of females) of weekly sports drink consumers reported drinking a sports drink on five or more days of the week. Similarly, 30.5\% of males and $25.7 \%$ of females who were classified as weekly energy drink consumers reported having an energy drink on five or more days of the week (data not shown).

For males and females, consumption of sports and energy drinks differed by educational achievement $(P<0.001$ or $P=0.02$ ) with those having a four-year post-secondary degree being least likely to report weekly consumption (Table 1). Beverage-specific differences were observed in males and females. Sports drink intake was significantly associated with race/ethnicity $(P=0.001)$, parental status $(P=0.02)$, relationship status $(P=0.03)$ and sensationseeking behaviours $(P=0.002)$ among males as well as with weight status $(P=0.006)$ among females. Energy drink intake was significantly associated with parental status $(P=0.002)$ and sensation-seeking behaviours $(P=0.03)$ among males as well as with student status $(P=0.01)$ and sensation-seeking behaviours $(P=0.01)$ among females.

\section{Adjusted associations of sports drink consumption with bealth behaviours}

For males and females, weekly sports drink consumption was significantly associated with higher consumption of sugarsweetened soda (both $P=0.01$ ) and $100 \%$ fruit juice ( $P<0.001$ and $P=0.001$, respectively), higher video game use $(P<0.001$ and $P=0.002$, respectively), binge drinking ( $P=0.01$ and $P=0.03$, respectively) and use of muscleenhancing substances (both $P<0 \cdot 001$; Table 2). The observed difference in video game use was particularly notable for males, with those who consumed sports drinks weekly spending an average of $2 \cdot 5$ additional hours per week playing video games compared with males who consumed 
Table 1 Young adults' ( $n$ 2287) consumption of sports and energy drinks by sociodemographic characteristics and enjoyment of sensationseeking behaviours; Project EAT-III (Eating and Activity in Teens and Young Adults), Minneapolis/St. Paul, MN, USA, 2008-2009

\begin{tabular}{|c|c|c|c|c|c|c|c|c|c|}
\hline & \multirow[b]{3}{*}{$n \dagger$} & \multicolumn{4}{|c|}{ Sports drinks* } & \multicolumn{4}{|c|}{ Energy drinks* } \\
\hline & & \multicolumn{2}{|l|}{ Males } & \multicolumn{2}{|c|}{ Females } & \multicolumn{2}{|l|}{ Males } & \multicolumn{2}{|l|}{ Females } \\
\hline & & $\begin{array}{c}\text { One or more } \\
\text { drink(s)/week } \\
(\%)\end{array}$ & $\begin{array}{c}P \\
\text { value } \neq\end{array}$ & $\begin{array}{l}\text { One or more } \\
\text { drink(s)/week } \\
(\%)\end{array}$ & $\begin{array}{c}P \\
\text { value } \neq\end{array}$ & $\begin{array}{c}\text { One or more } \\
\text { drink(s)/week } \\
(\%)\end{array}$ & $\begin{array}{c}P \\
\text { value } \neq\end{array}$ & $\begin{array}{l}\text { One or more } \\
\text { drink(s)/week } \\
(\%)\end{array}$ & $\begin{array}{c}P \\
\text { valueł }\end{array}$ \\
\hline Overall & 2287 & $44 \cdot 6$ & & $19 \cdot 9$ & & $26 \cdot 7$ & & $12 \cdot 2$ & \\
\hline Age (years) & & & 0.15 & & 0.07 & & 0.48 & & 0.11 \\
\hline $\begin{array}{l}20-24 \\
25-31\end{array}$ & $\begin{array}{r}707 \\
1580\end{array}$ & $\begin{array}{l}48.0 \\
43.1\end{array}$ & & $\begin{array}{l}22.9 \\
18.5\end{array}$ & & $\begin{array}{l}28.2 \\
26.1\end{array}$ & & $\begin{array}{l}14.4 \\
11.2\end{array}$ & \\
\hline Race/ethnicity & & & 0.001 & & 0.07 & & 0.14 & & 0.41 \\
\hline White & 1094 & $42 \cdot 3$ & & $17 \cdot 2$ & & $27 \cdot 1$ & & $13 \cdot 3$ & \\
\hline $\begin{array}{l}\text { Black or African } \\
\text { American }\end{array}$ & 420 & $47 \cdot 6$ & & $19 \cdot 4$ & & $24 \cdot 4$ & & $9 \cdot 2$ & \\
\hline Asian American & 442 & $37 \cdot 7$ & & $24 \cdot 2$ & & $22 \cdot 2$ & & $12 \cdot 8$ & \\
\hline Mixed/other & 304 & $58 \cdot 3$ & & $24 \cdot 0$ & & $32 \cdot 9$ & & $12 \cdot 6$ & \\
\hline $\begin{array}{l}\text { Educational } \\
\text { achievement }\end{array}$ & & & $<0.001$ & & $<0.001$ & & $<0.001$ & & 0.02 \\
\hline Some high school & 89 & $56 \cdot 2$ & & $36 \cdot 0$ & & $32 \cdot 4$ & & $12 \cdot 0$ & \\
\hline $\begin{array}{l}\text { High-school } \\
\text { degree or GED }\end{array}$ & 926 & $48 \cdot 3$ & & $23 \cdot 3$ & & $29 \cdot 8$ & & $15 \cdot 7$ & \\
\hline $\begin{array}{l}\text { 2-year post- } \\
\text { secondary degree }\end{array}$ & 568 & $47 \cdot 7$ & & $21 \cdot 9$ & & $30 \cdot 1$ & & 11.5 & \\
\hline $\begin{array}{l}\text { 4-year post- } \\
\text { secondary degree }\end{array}$ & 684 & $33 \cdot 6$ & & $12 \cdot 4$ & & $17 \cdot 4$ & & $8 \cdot 6$ & \\
\hline Student status & & & $0 \cdot 15$ & & 0.26 & & 0.07 & & 0.01 \\
\hline Student & 1504 & $41 \cdot 1$ & & $18 \cdot 2$ & & $22 \cdot 7$ & & $9 \cdot 0$ & \\
\hline Non-student & 762 & $45 \cdot 9$ & & $20 \cdot 8$ & & $28 \cdot 2$ & & $13 \cdot 7$ & \\
\hline Employment status & & & 0.96 & & 0.17 & & $0 \cdot 61$ & & 0.78 \\
\hline Not employed & 246 & $44 \cdot 0$ & & $23 \cdot 6$ & & $24 \cdot 6$ & & $13 \cdot 0$ & \\
\hline Part-time & 758 & $43 \cdot 6$ & & $21 \cdot 3$ & & $25 \cdot 4$ & & $12 \cdot 0$ & \\
\hline Full-time & 1137 & 44.5 & & $17 \cdot 7$ & & $28 \cdot 1$ & & $11 \cdot 1$ & \\
\hline Parental status & & & 0.02 & & 0.05 & & 0.002 & & 0.95 \\
\hline No children & 1528 & 42.5 & & $18 \cdot 3$ & & $24 \cdot 0$ & & $12 \cdot 3$ & \\
\hline One or more child & 741 & $50 \cdot 8$ & & $22 \cdot 8$ & & $34 \cdot 0$ & & $12 \cdot 2$ & \\
\hline Relationship status & & & 0.03 & & 0.06 & & 0.24 & & 0.58 \\
\hline $\begin{array}{l}\text { Single/casually } \\
\text { dating }\end{array}$ & 837 & $48 \cdot 1$ & & $20 \cdot 6$ & & $28 \cdot 2$ & & $12 \cdot 8$ & \\
\hline $\begin{array}{l}\text { Married/committed } \\
\text { partner }\end{array}$ & 1422 & $41 \cdot 2$ & & $19 \cdot 4$ & & $25 \cdot 0$ & & $11 \cdot 7$ & \\
\hline $\begin{array}{l}\text { Sensation-seeking } \\
\text { behaviour§ }\end{array}$ & & & 0.002 & & 0.13 & & 0.03 & & 0.01 \\
\hline Low enjoyment & 1811 & $41 \cdot 2$ & & $19 \cdot 1$ & & 24.5 & & $11 \cdot 2$ & \\
\hline High enjoyment & 458 & 51.9 & & $24 \cdot 2$ & & $31 \cdot 0$ & & $18 \cdot 0$ & \\
\hline Weight status & & & 0.06 & & 0.006 & & 0.08 & & 0.06 \\
\hline Not overweight & 1039 & $40 \cdot 8$ & & $17 \cdot 0$ & & $23 \cdot 0$ & & $10 \cdot 7$ & \\
\hline Overweight & 632 & $46 \cdot 9$ & & $18 \cdot 2$ & & $29 \cdot 7$ & & $10 \cdot 9$ & \\
\hline Obese & 483 & $49 \cdot 7$ & & $26 \cdot 0$ & & 28.5 & & $16 \cdot 1$ & \\
\hline
\end{tabular}

GED, General Equivalency Diploma.

${ }^{*}$ All percentages are weighted to reflect the probability of responding to the EAT-III survey.

†Sample size for different variables might vary from total sample size because of missing responses and rounding of weighted frequencies

$\ddagger P$ values represent testing for independence of sociodemographic categorization and frequency of shared meals in the past week by the $X^{2}$ test.

$\S$ Defined by report of enjoyment (low = 'not at all' or 'a little'; high = 'quite a bit' or 'very much') in doing things that are a little dangerous.

sports drinks less than once weekly. Among males only, weekly sports drink consumption was also significantly associated with higher milk consumption $(P<0 \cdot 001)$, higher total and moderate-to-vigorous physical activity (both $P<0.001)$, higher use of muscle-enhancing behaviours $(P<0.001)$ and marijuana use $(P=0.01)$. Among females only, weekly sports drink consumption was significantly associated with less frequent breakfast consumption $(P<0.001)$ and use of unhealthy weight-control behaviours $(P=0.003)$. Similar patterns were observed for males and females in models of substance-use behaviours that additionally accounted for sensation-seeking behaviour, with only two notable exceptions (data not shown). Among females, the relationship between weekly sports drink consumption and binge drinking was attenuated and no longer statistically significant $(P=0.07)$ while an association with steroid use emerged $(P=0.02)$.

\section{Adjusted associations of energy drink consumption with health behaviours}

For males and females, weekly energy drink consumption was significantly associated with higher consumption of 
Table 2 Sports drink consumption and adjusted associations with health behaviours and attitudes among young adult males and females*; Project EAT-III (Eating and Activity in Teens and Young Adults), Minneapolis/St. Paul, MN, USA, 2008-2009

\begin{tabular}{|c|c|c|c|c|c|c|}
\hline & \multicolumn{3}{|c|}{ Males $(n$ 1030) } & \multicolumn{3}{|c|}{ Females ( $n$ 1257) } \\
\hline & $\begin{array}{l}\text { Less than one } \\
\text { drink/week }\end{array}$ & $\begin{array}{l}\text { One or more } \\
\text { drink(s)/week }\end{array}$ & $P$ value & $\begin{array}{l}\text { Less than one } \\
\text { drink/week }\end{array}$ & $\begin{array}{l}\text { One or more } \\
\text { drink(s)/week }\end{array}$ & $P$ value \\
\hline \multicolumn{7}{|l|}{ Eating behaviours } \\
\hline Sugar-sweetened soda (servings/d) & 0.7 & 0.8 & 0.01 & 0.5 & 0.6 & 0.01 \\
\hline Coffee/tea (servings/d) & 0.6 & 0.4 & 0.37 & 0.6 & 0.5 & 0.38 \\
\hline Fruit juice (servings/d) & 0.7 & 1.0 & $<0.001$ & 0.7 & 0.9 & 0.001 \\
\hline Milk (servings/d) & 0.9 & 1.3 & $<0.001$ & 0.9 & 0.9 & 0.48 \\
\hline Breakfast (d/week) & 3.6 & $3 \cdot 3$ & 0.23 & $4 \cdot 2$ & 3.6 & $<0.001$ \\
\hline \multicolumn{7}{|l|}{ Physical activity and media use } \\
\hline Total activity (h/week) & $7 \cdot 1$ & 9.5 & $<0.001$ & $6 \cdot 1$ & $6 \cdot 6$ & 0.08 \\
\hline Moderate-to-vigorous activity (h/week) & $4 \cdot 2$ & $5 \cdot 9$ & $<0.001$ & $3 \cdot 3$ & $3 \cdot 8$ & 0.07 \\
\hline Muscle-enhancing behaviourst (score) & 4.7 & $5 \cdot 3$ & $<0.001$ & 4.6 & 4.8 & 0.10 \\
\hline Video game playing (h/week) & $7 \cdot 1$ & $9 \cdot 6$ & $<0.001$ & $1 \cdot 1$ & $1 \cdot 7$ & 0.002 \\
\hline Television viewing (h/week) & $20 \cdot 6$ & $20 \cdot 6$ & 0.31 & $19 \cdot 6$ & $20 \cdot 0$ & 0.51 \\
\hline \multicolumn{7}{|l|}{ Weight-control behaviours } \\
\hline Dieting (\%) & 31.4 & $29 \cdot 6$ & 0.58 & $57 \cdot 0$ & 63.6 & 0.11 \\
\hline $\begin{array}{l}\text { Unhealthy weight-control } \\
\text { behaviours } \ddagger(\%)\end{array}$ & $30 \cdot 6$ & $29 \cdot 1$ & 0.63 & 53.9 & $66 \cdot 2$ & 0.003 \\
\hline $\begin{array}{l}\text { Extreme weight-control } \\
\text { behaviours§ }(\%)\end{array}$ & 4.5 & $4 \cdot 3$ & $0 \cdot 89$ & $14 \cdot 6$ & $15 \cdot 7$ & 0.70 \\
\hline \multicolumn{7}{|l|}{ Sleep patterns } \\
\hline Inadequate sleep (\%) & $10 \cdot 3$ & $14 \cdot 6$ & 0.05 & 8.6 & $9 \cdot 1$ & 0.83 \\
\hline Trouble sleeping (\%) & $63 \cdot 6$ & $62 \cdot 7$ & 0.78 & $68 \cdot 8$ & 73.4 & 0.21 \\
\hline \multicolumn{7}{|l|}{ Substance use and risk taking } \\
\hline Cigarette smoking (\%) & $27 \cdot 7$ & $28 \cdot 2$ & 0.86 & $20 \cdot 9$ & $23 \cdot 3$ & 0.47 \\
\hline Binge drinking (\%) & 58.9 & $67 \cdot 1$ & 0.01 & $44 \cdot 3$ & $53 \cdot 1$ & 0.03 \\
\hline Marijuana use (\%) & $25 \cdot 1$ & $33 \cdot 2$ & 0.01 & $15 \cdot 7$ & $17 \cdot 0$ & 0.66 \\
\hline Steroid use (\%) & 1.8 & 3.6 & 0.07 & 0.1 & 0.2 & 0.05 \\
\hline Muscle-enhancing substance usell (\%) & $8 \cdot 3$ & $16 \cdot 3$ & $<0.001$ & $1 \cdot 7$ & $5 \cdot 4$ & $<0.001$ \\
\hline
\end{tabular}

*Weighted regression model is adjusted for young adult age, race/ethnicity, educational achievement, student status, employment status, parental status, relationship status and weight status.

†Muscle-enhancing behaviours included: (i) changed my eating; and (ii) exercised more.

†Unhealthy weight-control behaviours included: (i) fasted; (ii) ate very little food; (iii) used a food substitute (powder or a special drink); (iv) skipped meals; and (v) smoked more cigarettes.

§Extreme weight-control behaviours included: (i) took diet pills; (ii) made myself vomit; (iii) used laxatives; and (iv) used diuretics.

IIAny muscle-building substance other than steroids (e.g. creatine, amino acids, hydroxyl methylbutyrate, DHEA (dehydroepiandrosterone), growth hormone).

sugar-sweetened soda $(P=0.003$ and $P=0.005$, respectively), less frequent breakfast consumption $(P<0 \cdot 001$ and $P=0 \cdot 02$, respectively $)$, higher video game use $(P<0 \cdot 001$ and $P=0.008$, respectively), use of unhealthy weightcontrol behaviours (both $P<0.001$ ), trouble sleeping ( $P=0.007$ and $P=0.03$, respectively), cigarette smoking (both $P<0.001$ ) and binge drinking (both $P<0.001$; Table 3). As an example, the observed prevalence of unhealthy weight-control behaviours among females who consumed energy drinks at least weekly was $77.4 \%$ compared with $53.6 \%$ among those who consumed energy drinks less than once weekly. Among males only, weekly energy drink consumption was also significantly associated with total and moderate-to-vigorous physical activity $(P=0.01$ and $P=0.04$, respectively), use of muscle-enhancing behaviours $(P=0.003)$, inadequate sleep $(P<0.001)$, steroid use $(P=0.003)$ and other muscleenhancing substance use $(P=0 \cdot 001)$. Among females only, weekly energy drink consumption was significantly associated with higher television viewing $(P=0.004)$, dieting $(P<0.001)$ and marijuana use $(P=0.03)$. Similar patterns were observed for males and females in models of substance-use behaviours that additionally accounted for sensation-seeking behaviour (data not shown). Only the relationship between weekly energy drink consumption and marijuana use in females was attenuated and no longer statistically significant $(P=0 \cdot 08)$.

\section{Discussion}

The present study described sports and energy drink consumption among a sample of young adults and identified linkages to health-risk behaviours that might be important to understand in developing interventions to address consumption of these beverages. The results showed that nearly one of three young adults consumed a sports drink and one of five young adults consumed an energy drink at least once weekly. Males, as well as young adults who did not report a four-year post-secondary degree, were most likely to report consumption this often. 
Table 3 Energy drink consumption and adjusted associations with health behaviours and attitudes among young adult males and females*; Project EAT-III (Eating and Activity in Teens and Young Adults), 2008-2009

\begin{tabular}{|c|c|c|c|c|c|c|}
\hline & \multicolumn{3}{|c|}{ Males ( $n$ 1030) } & \multicolumn{3}{|c|}{ Females ( $n$ 1257) } \\
\hline & $\begin{array}{l}\text { Less than one } \\
\text { drink/week }\end{array}$ & $\begin{array}{l}\text { One or more } \\
\text { drink(s)/week }\end{array}$ & $P$ value & $\begin{array}{l}\text { Less than one } \\
\text { drink/week }\end{array}$ & $\begin{array}{l}\text { One or more } \\
\text { drink(s)/week }\end{array}$ & $P$ value \\
\hline \multicolumn{7}{|l|}{ Eating behaviours } \\
\hline Sugar-sweetened soda (servings/d) & 0.7 & 0.9 & 0.003 & 0.4 & 0.7 & 0.005 \\
\hline Coffee/tea (servings/d) & 0.5 & 0.5 & 0.19 & 0.6 & 0.5 & 0.91 \\
\hline Fruit juice (servings/d) & 0.8 & 0.8 & 0.26 & 0.7 & 0.7 & 0.83 \\
\hline Milk (servings/d) & 1.2 & 0.9 & 0.15 & 1.0 & 0.8 & 0.44 \\
\hline Breakfast (d/week) & $3 \cdot \overline{6}$ & 3.0 & $<0.001$ & $4 \cdot 2$ & $3 \cdot 6$ & 0.02 \\
\hline \multicolumn{7}{|l|}{ Physical activity and media use } \\
\hline Total activity (h/week) & 7.9 & $9 \cdot 0$ & 0.01 & $6 \cdot 1$ & $6 \cdot 8$ & 0.14 \\
\hline Moderate-to-vigorous activity (h/week) & 4.8 & 5.4 & 0.04 & 3.4 & 3.7 & 0.64 \\
\hline Muscle-enhancing behaviours $\dagger$ (score) & 4.9 & $5 \cdot 3$ & 0.003 & 4.6 & $4 \cdot 7$ & 0.63 \\
\hline Video game playing (h/week) & $7 \cdot 4$ & $10 \cdot 4$ & $<0.001$ & $1 \cdot 1$ & 1.9 & 0.008 \\
\hline Television viewing (h/week) & $20 \cdot 9$ & 19.7 & 0.21 & $19 \cdot 3$ & $22 \cdot 2$ & 0.004 \\
\hline \multicolumn{7}{|l|}{ Weight-control behaviours } \\
\hline Dieting (\%) & $29 \cdot 3$ & $34 \cdot 2$ & 0.19 & $56 \cdot 5$ & $73 \cdot 0$ & $<0.001$ \\
\hline $\begin{array}{l}\text { Unhealthy weight-control } \\
\text { behaviours } \ddagger(\%)\end{array}$ & 24.9 & $45 \cdot 3$ & $<0.001$ & $53 \cdot 6$ & $77 \cdot 4$ & $<0.001$ \\
\hline $\begin{array}{l}\text { Extreme weight-control } \\
\text { behaviours§ }(\%)\end{array}$ & $3 \cdot 8$ & $6 \cdot 7$ & 0.05 & $14 \cdot 2$ & $17 \cdot 9$ & 0.32 \\
\hline \multicolumn{7}{|l|}{ Sleep patterns } \\
\hline Inadequate sleep (\%) & $10 \cdot 1$ & 18.5 & $<0.001$ & $8 \cdot 2$ & $12 \cdot 2$ & 0.19 \\
\hline Trouble sleeping (\%) & 60.5 & $70 \cdot 7$ & 0.007 & 68.7 & $78 \cdot 1$ & 0.03 \\
\hline \multicolumn{7}{|l|}{ Substance use and risk taking } \\
\hline Cigarette smoking (\%) & $24 \cdot 3$ & 38.2 & $<0.001$ & $18 \cdot 4$ & $48 \cdot 6$ & $<0.001$ \\
\hline Binge drinking $(\%)$ & 58.5 & 73.4 & $<0.001$ & 44.2 & 62.9 & $<0.001$ \\
\hline Marijuana use (\%) & $26 \cdot 7$ & $33 \cdot 4$ & 0.06 & $15 \cdot 1$ & $23 \cdot 0$ & 0.03 \\
\hline Steroid use (\%) & $1 \cdot 7$ & $5 \cdot 1$ & 0.003 & 0.1 & 0.2 & 0.17 \\
\hline Muscle-enhancing substance usell (\%) & 9.9 & $18 \cdot 2$ & 0.001 & $2 \cdot 2$ & 4.0 & 0.21 \\
\hline
\end{tabular}

*Weighted regression model is adjusted for young adult age, race/ethnicity, educational achievement, student status, employment status, parental status, relationship status and weight status.

†Muscle-enhancing behaviours included: (i) changed my eating; and (ii) exercised more.

¥Unhealthy weight-control behaviours included: (i) fasted; (ii) ate very little food; (iii) used a food substitute (powder or a special drink); (iv) skipped meals; and (v) smoked more cigarettes.

§Extreme weight-control behaviours included: (i) took diet pills; (ii) made myself vomit; (iii) used laxatives; and (iv) used diuretics.

IAny muscle-building substance other than steroids (e.g. creatine, amino acids, hydroxyl methylbutyrate, DHEA (dehydroepiandrosterone), growth hormone).

Consuming one or more sports drinks or energy drinks weekly was associated with higher sugar-sweetened soda intake, video game use and binge drinking among men and women. In addition, weekly energy drink consumption was linked to cigarette smoking as well as a lower frequency of eating breakfast, a higher prevalence of unhealthy weight-control behaviours and trouble sleeping.

These study findings complement recent national data that have indicated consumption of sports and energy drinks is climbing among young adults and raised concerns about the health effects of caffeine ${ }^{(3,36)}$. The caffeine content of energy drinks has been the focus of particular concern as many of them contain $70-80 \mathrm{mg}$ per $8 \mathrm{floz}(237 \mathrm{ml})$ serving or approximately three times the concentration found in cola drinks; little is known about the interactions between caffeine and other common ingredients (e.g. taurine, guarana) and there are no requirements for safety testing or warning labels on these drinks when they are often sold as dietary supplements in the $\mathrm{USA}^{(8,37)}$. There is no official recommendation for caffeine intake in the USA; however, it is recommended that women of childbearing age limit their daily intake to less than $300 \mathrm{mg}$ and Health Canada advises that the general adult population not exceed $400 \mathrm{mg}^{(38)}$. Continued monitoring of caffeine intakes will be important if energy drink consumption continues to rise as it has in recent years.

Additionally, the findings build on a growing number of studies that have raised concerns about the contribution of sugar-sweetened beverages to overall energy, added sugar and $\mathrm{Na}$ consumption among young adults ${ }^{(3,16,39)}$. The American Heart Association recommends that energy from added sugar be limited to approximately $418 \mathrm{~kJ} / \mathrm{d}$ $(100 \mathrm{kcal} / \mathrm{d})$ for women and $628 \mathrm{~kJ} / \mathrm{d}(150 \mathrm{kcal} / \mathrm{d})$ for men $^{(40)}$. For $\mathrm{Na}$, it is recommended that intake also be limited to no more than $1500-2400 \mathrm{mg} / \mathrm{d}^{(41)}$. Some brands of sports drinks contain as much as $335 \mathrm{~kJ}$ (80 kcal), $15 \mathrm{~g}$ sugar and $200 \mathrm{mg} \mathrm{Na}$ per $8 \mathrm{floz}(237 \mathrm{ml})$ serving $^{(4,42)}$. Likewise, depending on the brand, energy drinks contain as much as $586 \mathrm{~kJ}$ (140 kcal), $35 \mathrm{~g}$ sugar and $340 \mathrm{mg} \mathrm{Na}$ per $8 \mathrm{floz}(237 \mathrm{ml})^{(4,42)}$. There is compelling scientific evidence linking sugar-sweetened beverage consumption to increased risk for obesity, type 2 diabetes and CVD in the 
overall population and particularly among young adults $^{(1,43,44)}$. The combination of added sugars and citric acid in sports and energy drinks may also increase risk for poor dental health ${ }^{(4)}$. Citric acid is highly erosive because its demineralizing effects on dental enamel continue even after consumption of a beverage and $\mathrm{pH}$ neutralization.

The identified associations with patterns of substance use are in line with and build on previous studies among young adults, which have primarily focused on alcohol consumption among college students ${ }^{(13,14,33,34,45-48)}$. In the current study, linkages between energy drink consumption and binge drinking were observed in a diverse population that included both students and non-students. Additionally, the current study was among the first to examine and identify associations of energy drink consumption with smoking cigarettes, marijuana use and steroid use ${ }^{(16,34,49)}$. The examination of linkages between sports and energy drink consumption and the use of other muscle-enhancing substances was particularly novel. The findings raise new concerns about subgroups of young adults who may be more likely to consume energy drinks and use various substances that pose health risks. Consuming high doses of caffeine in energy drinks along with alcohol or other substances is especially problematic as caffeine may lead individuals to underestimate substancerelated impairments ${ }^{(50,51)}$. With few exceptions, associations between sports drink and energy drink consumption and substance use were observed above and beyond a tendency to engage in sensation-seeking behaviours and thus our results suggest they are not just a mere representation of overall risk-behaviour patterns. Only one other study among US adults was found that similarly reported linkages between energy drink consumption and substance use persist after controlling for risk-taking propensity $^{(33)}$.

Our findings that showed sports and energy drink consumption was more prevalent among young men and particularly those who spend more time engaged in physical activity, further reflect the initial targeted promotion of these drinks to male athletes ${ }^{(52)}$. However, recent reports indicate the target market is broadening as new products are being developed for women and those who are concerned with limiting carbohydrates (e.g. Damzl Fuel $\left.{ }^{\circledR}, G 2^{\circledR}\right)^{(52)}$. The findings suggest the need to address the aggressive and targeted marketing strategies used by sports and energy drink companies in an environment of limited product regulation ${ }^{(8,37,52,53)}$. Marketing for sports and energy drinks is, in general, targeted towards teenagers and young adults aged 18-34 years through cross-promotional tactics such as integrating the product with extreme sporting events and popular music icons and product placement in youthoriented media (e.g. video games, social networking sites $)^{(8,52,53)}$. In addition, energy drink companies often use imaginative product names (e.g. Full Throttle, Monster Energy $^{\circledR}$, Cocaine $^{\circledR}$ ) that appeal to this demographic and problematically some names also glamorize substance use.
The energy drink Cocaine is an example of a product that has further glorified substance use in promotions by posting video clips on the company website that showed consumers 'snorting' the liquid beverage ${ }^{(37)}$.

The development of these sub-markets may play a role in explaining our new findings that linked sports and energy drink consumption to the use of weight-control behaviours. Sports drinks were linked to breakfast skipping and the use of less extreme forms of unhealthy weight-control behaviours (e.g. eating very little food) only among females. Energy drinks were linked to breakfast skipping and less extreme forms of unhealthy weight-control behaviours among both males and females, as well as dieting among females. These findings point to a need for further research to identify how sports and energy drinks are used by young adults seeking to lose weight and how this use may hinder their weight-loss efforts or even worse pose additional health risks. For example, little is known about the interactions between substances found in diet pills, caffeine and other energy drink ingredients and whether those interactions may lead to harm, particularly among individuals with certain medial conditions or who take certain prescription medications ${ }^{(36,54)}$. Young adults who might alternatively consume a sports or energy drink while exercising could easily consume a large portion of the energy they expend if they do not select a low-sugar or sugar-free drink (e.g. one $24 \mathrm{fl} \mathrm{oz}(710 \mathrm{ml})$ can of Monster Energy drink contains $1381 \mathrm{~kJ}(330 \mathrm{kcal}))$.

A number of strengths and limitations are important to address in drawing conclusions from the present study. The early years of adulthood are understudied and the large sample of young adult participants was diverse in terms of race, educational achievement, student status and parental status ${ }^{(6)}$. The study also used a comprehensive survey and validated FFQ to identify sociodemographic characteristics and health-risk behaviours associated with sports and energy drink consumption among young adults; however, several factors were assessed with brief measures to avoid excess participant burden. The single items used to separately assess intake of sports and energy drinks for the current study are particularly noteworthy, as only frequency of consumption was measured while there are numerous types of these drinks on the market that vary considerably in nutritional composition and volume. As the measures of sports and energy drink consumption were not included on previous Project EAT surveys, the study was further limited by a cross-sectional design. The results may not be generalizable to other young adult populations outside the Midwest. Additional research using longitudinal designs and in other population samples will be needed to establish temporality and confirm that the observed associations are broadly relevant.

Despite the need for future research, the results suggest health professionals should be aware of the clustering of sports and energy drink consumption with other 
unhealthy behaviours. The results indicate a spectrum of health behaviours that impact obesity and chronic disease should be considered in the design of programmes and services for young adults, including eating habits, physical activity, media use, sleep patterns and substance use. For example, young adults who report substance use should be provided with anticipatory health guidance regarding the masking effects of caffeine in energy drinks on substance-related impairments. Similarly, providers who encounter young adults with weight-loss goals should counsel them regarding eating and drinking habits that will best enable them to achieve appropriate changes in weight while maintaining good health. Finally, health professionals can also have a positive impact on population health through advocacy addressing the targeted marketing of sports and energy drinks to young adults and lack of US labelling regulations for these products.

\section{Acknowledgements}

Financial support: This work was supported by the National Heart, Lung, and Blood Institute (grant number R01HL084064; Principal Investigator D.N.-S.). Additional salary support was provided by the National Cancer Institute (grant number K07CA126837; Principal Investigator M.N.L.). The content is solely the responsibility of the authors and does not necessarily represent the official views of the National Heart, Lung, and Blood Institute; the National Cancer Institute; or the National Institutes of Health. Conflict of interest: None. Authorship: N.L. conducted the statistical analysis and drafted the manuscript. M.N.L. and M.S. helped to conceptualize the analysis plan. D.N.-S. conceptualized the larger Project EAT-III study design and oversaw data collection. All authors contributed to the interpretation of results and manuscript revisions. Ethics of human subject participation: All study protocols were approved by the University of Minnesota's Institutional Review Board Human Subjects Committee.

\section{References}

1. Malik V, Popkin B, Bray G et al. (2010) Sugar-sweetened beverages, obesity, type 2 diabetes mellitus, and cardiovascular disease risk. Circulation 121, 1356-1364.

2. Tahmassebi J, Duggal M, Malik-Kotru G et al. (2006) Soft drinks and dental health: a review of the current literature. $J$ Dent 34, 2-11.

3. Han E \& Powell L (2013) Consumption patterns of sugarsweetened beverages in the United States. J Acad Nutr Diet 113, 43-53.

4. Committee on Nutrition \& Council on Sports Medicine and Fitness (2011) Sports drinks and energy drinks for children and adolescents: are they appropriate? Pediatrics 127, 1182-1189.

5. Heneghan C, Gill P, O'Neill B et al. (2012) Mythbusting sports and exercise products. BMJ 345, e4848.
6. Nelson MC, Story M, Larson NI et al. (2008) Emerging adulthood and college-aged youth: an overlooked age for weight-related behavior change. Obesity (Silver Spring) 16, 2205-2211.

7. Cohen D (2012) The truth about sports drinks. BMJ $\mathbf{3 4 5}$, e4737.

8. Seifert S, Schaechter J, Hershorin E et al. (2011) Health effects of energy drinks on children, adolescents, and young adults. Pediatrics 127, 511-528.

9. Wolk B, Ganetsky M \& Babu K (2012) Toxicity of energy drinks. Curr Opin Pediatr 24, 243-251.

10. Nordt S, Vilke G, Clark R et al. (2012) Energy drink use and adverse effects among emergency department patients. J Community Health 37, 976-981.

11. Campbell B, Wilborn C, Bounty PL et al. (2013) International Society of Sports Nutrition position stand: energy drinks. J Int Soc Sports Nutr 10, 1.

12. Berger L, Fendrich M, Chen H-Y et al. (2011) Sociodemographic correlates of energy drink consumption with and without alcohol: results of a community survey. Addict Behav 36, 516-519.

13. Velazquez C, Poulos N, Latimer L et al. (2012) Associations between energy drink consumption and alcohol use behaviors among college students. Drug Alcohol Depend 123, $167-172$.

14. Marczinski C (2011) Alcohol mixed with energy drinks: consumption patterns and motivations for use in US college students. Int J Environ Res Public Health 8, $3232-3245$.

15. VanKim NA, Larson N \& Laska MN (2012) Emerging adulthood: a critical age for preventing excess weight gain? Adolesc Med State Art Rev 23, 571-588.

16. Park S, Onufrak S, Blanck H et al. (2013) Characteristics associated with consumption of sports and energy drinks among US adults: National Health Interview Survey, 2010. J Acad Nutr Diet 113, 112-119.

17. Neumark-Sztainer D, Story M, Hannan P et al. (2002) Overweight status and eating patterns among adolescents: where do youth stand in comparison to the Healthy People 2010 Objectives? Am J Public Health 92, 844-851.

18. Neumark-Sztainer D, Croll J, Story M et al. (2002) Ethnic/ racial differences in weight-related concerns and behaviors among adolescent girls and boys: findings from Project EAT. J Psychosom Res 53, 963-974.

19. Larson N, Neumark-Sztainer D, Harwood E et al. (2011) Do young adults participate in surveys that 'go green'? Response rates to a web and mailed survey of weightrelated health behaviors. Int J Child Health Hum Dev 4, 225-237.

20. Larson N, Neumark-Sztainer D, Story M et al. (2011) Identifying correlates of young adults' weight behavior: survey development. Am J Health Behav 35, 712-725.

21. Godin G \& Shephard RJ (1985) A simple method to assess exercise behavior in the community. Can J Appl Sport Sci 10, 141-146.

22. Gortmaker SL, Peterson K, Wiecha J et al. (1999) Reducing obesity via a school-based interdisciplinary intervention among youth: Planet Health. Arch Pediatr Adolesc Med 153 , 409-418.

23. Nelson M, Neumark-Sztainer D, Hannan P et al. (2006) Longitudinal and secular trends in physical activity and sedentary behavior during adolescence. Pediatrics 118, e1627-e1634.

24. Neumark-Sztainer D, Wall M, Guo J et al. (2006) Obesity, disordered eating, and eating disorders in a longitudinal study of adolescents: how do dieters fare five years later? J Am Diet Assoc 106, 559-568.

25. Pasch K, Laska M, Lytle L et al. (2010) Adolescent sleep, risk behaviors, and depressive symptoms: are they linked? $A m \mathrm{~J}$ Health Behav 34, 237-248. 
26. Meyer K, Wall M, Larson N et al. (2012) Sleep duration and BMI in a sample of young adults. Obesity (Silver Spring) 20 , 1279-1287.

27. Harvard School of Public Health, Nutrition Department (n.d.) HSPH Nutrition Department's File Download Site. https:// regepi.bwh.harvard.edu/health/FFQ/files/2007\%20GRID\%20 FFQ.pdf (accessed December 2014).

28. Feskanich D, Rimm E, Giovannucci E et al. (1993) Reproducibility and validity of food intake measurements from a semiquantitative food frequency questionnaire. $\mathrm{J} \mathrm{Am} \mathrm{Diet}$ Assoc 93, 790-796.

29. Rimm E, Giovannucci E, Stampfer M et al. (1992) Reproducibility and validity of an expanded self-administered semiquantitative food frequency questionnaire among male health professionals. Am J Epidemiol 135, 1114-1126.

30. Expert Panel on the Identification, Evaluation, and Treatment of Overweight and Obesity in Adults (1998) Executive summary of the Clinical Guidelines on the Identification, Evaluation, and Treatment of Overweight and Obesity in Adults. Arch Intern Med 158, 1855-1867.

31. Emond J, Gilbert-Diamond D, Tanski S et al. (2014) Energy drink consumption and the risk of alcohol use disorder among a national sample of adolescents and young adults. J Pediatr 165, 1194-1200.

32. Field A, Sonneville K, Falbe J et al. (2014) Association of sports drinks with weight gain among adolescents and young adults. Obesity (Silver Spring) 22, 2238-2243.

33. Brache K \& Stockwell $T$ (2011) Drinking patterns and risk behaviors associated with combined alcohol and energy drink consumption in college drinkers. Addict Behav 36, $1133-1140$.

34. Miller K (2008) Energy drinks, race, and problem behaviors among college students. J Adolesc Health 43, 490-497.

35. Little R (1986) Survey nonresponse adjustments for estimates of means. Int Stat Rev 54, 139-157.

36. Pray L, Yaktine A, Pankevich D et al. (2014) Caffeine in Food and Dietary Supplements: Examining Safety: Workshop Summary. Washington, DC: National Academies Press.

37. Reissig C, Strain E \& Griffiths R (2009) Caffeinated energy drinks - a growing problem. Drug Alcohol Depend 99, $1-10$

38. Kaiser L \& Allen L, American Dietetic Association (2008) Position of the American Dietetic Association: nutrition and lifestyle for a healthy pregnancy outcome. J Am Diet Assoc 108, 553-561.

39. West D, Bursac Z, Quimby D et al. (2006) Self-reported sugar-sweetened beverage intake among college students. Obesity (Silver Spring) 14, 1825-1831.

40. Johnson R, Appel L, Brands M et al. (2009) Dietary sugars intake and cardiovascular health: a scientific statement from the American Heart Association. Circulation 120, 1011-1020.

41. Eckel R, Jakicic J, Ard J et al. (2014) 2013 AHA/ACC guideline on lifestyle management to reduce cardiovascular risk: a report of the American College of Cardiology/ American Heart Association task force on practice guidelines. J Am Coll Cardiol 63, 2960-2984.

42. Yale Rudd Center for Food Policy and Obesity (2011) Sugary Drink f.a.c.t.s.: Food Advertising to Children and Teens Score. New Haven, CT: Rudd Center for Food Policy and Obesity.

43. Bermudez O \& Gao X (2010) Greater consumption of sweetened beverages and added sugars is associated with obesity among US young adults. Ann Nutr Metab 57, 211-218.

44. Hu F (2013) Resolved: there is sufficient scientific evidence that decreasing sugar-sweetened beverage consumption will reduce the prevalence of obesity and obesity-related diseases. Obes Rev 14, 606-619.

45. Woolsey C, Waigandt A \& Beck N (2010) Athletes and energy drinks: reported risk-taking and consequences from the combined use of alcohol and energy drinks. J Appl Sport Psychol 22, 65-71.

46. Oteri A, Salvo F, Caputi A et al. (2007) Intake of energy drinks in association with alcoholic beverages in a cohort of students of the School of Medicine of the University of Messina. Alcohol Clin Exp Res 31, 1677-1680.

47. Spierer D, Blanding N \& Santella A (2014) Energy drink consumption and associated health behaviors among university students in an urban setting. $J$ Community Health 39, 132-138.

48. Malinauskas B, Aeby V, Overton R et al. (2007) A survey of energy drink consumption patterns among college students. Nutr J 6, 35.

49. Snipes D \& Benotsch E (2013) High-risk cocktails and highrisk sex: examining the relation between alcohol mixed with energy drink consumption, sexual behavior, and drug use in college students. Addict Behav 38, 1418-1423.

50. Ferreira S, de Mello MT, Pompéia S et al. (2006) Effects of energy drink ingestion on alcohol intoxication. Alcohol Clin Exp Res 30, 598-605.

51. Marczinski C \& Fillmore M (2006) Clubgoers and their trendy cocktails: implications of mixing caffeine into alcohol on information processing and subjective reports of intoxication. Exp Clin Psychopharmacol 14, 450-458.

52. Heckman M, Sherry K \& Gonzalez de Mejia E (2010) Energy drinks: an assessment of their market size, consumer demographics, ingredient profile, functionality, and regulations in the United States. Compreh Rev Food Sci Food Saf $\mathbf{9}$ 303-317.

53. Dietz W \& Dorfman L (2014) How far will big soda go to keep people from drinking water? http://www.beyondchron.org/ news/index.php?itemid=12363 (accessed December 2014).

54. Seifert S, Seifert S, Schaechter J et al. (2013) An analysis of energy-drink toxicity in the National Poison Data System. Clin Toxicol 51, 566-574. 